\title{
INDIGENOUS KNOWLEDGE: BEYOND PROTECTION, TOWARDS DIALOGUE
}

\section{MICHAEL DAVIS}

Jumbunna Indigenous House of Learning, University of Technology Sydney, PO Box 123, Broadway, New South Wales, 2007, Australia

\section{Abstract}

This paper interrogates the emphasis on devising regimes for protection of Indigenous knowledge, based on narrowly defined concepts of property, especially intellectual property in legislative and policy discussions and debates and programs of work on Indigenous knowledge. Commenting on the classificatory and typological tendencies of legislative protection regimes, the paper argues for a shift from this emphasis on protection, toward the creation of a space for engagement between Indigenous, and other knowledge traditions, wherein concepts of dialogue, negotiation and agreement-making can occur. The paper supports its argument by reviewing selected legal instruments such as the 2003 UNESCO Convention on the Safeguarding of the Intangible Heritage, and drawing on some of the author's experience working with Aboriginal people in the Kimberley.

\section{Introduction}

Debates on Indigenous knowledge are gathering pace in international forums such as the United Nations Environment Program's Convention on Biological Diversity (CBD), the World Intellectual Property Organisation (WIPO), and others. Increasingly, this activity is considering ways to develop legislative regimes and mechanisms for protection of Indigenous knowledge. Much of this activity focuses on the role of intellectual property rights (IPRs) in regulating and protecting Indigenous knowledge (e.g., Brown, 2005; Davis, 2006). At the same time, many assessments and critiques of IPR regimes in terms of their relevance for protecting Indigenous knowledge look to the development of alternative or sui generis approaches (Posey \& Dutfield, 1996).

In this paper, I interrogate the focus on legislative approaches, especially around notions of "protection" of Indigenous knowledge, and suggest a shift away from this focus towards developing a space for dialogue and engagement between Indigenous and other knowledge traditions. In earlier work, I argued for a review of the kind of language and discourse employed in legislative and policy debates and discussions, in order to find ways of enhancing comparison and interaction between Indigenous and Western knowledge systems (Davis, 2006). I want to extend that argument to develop further an idea for dialogue and negotiation, in what might be called a "negotiating space" for Indigenous, and other knowledge traditions. I argue that Indigenous knowledge, by its nature, contains important qualities that allow a possibility for such dialogue and negotiation. This argument draws support from a body of writings that interrogate the perceived dichotomy between "Indigenous knowledge" on the one hand, and other forms of knowledge, including "Western science" on the other hand (e.g., Agrawal, 1995; Ellen \& Harris, 2002). In critiquing the emphasis on legislative mechanisms concerned with protection of property rights in Indigenous knowledge, Gibson (2005, p. 11) for example, posits a consideration of the notion of "community resources" in order to "overcome the presumption of property and the economic value of information that inheres in such terms as 'traditional knowledge". Pratt's (1992) use of the term "contact zone" is useful as a vehicle for conceptualising the meeting points between cultures and knowledge systems. In her scheme "contact zones" are "social spaces where disparate cultures 
meet, clash, and grapple with each other, often in highly asymmetrical relations of domination and subordination" (Pratt, 1992, p. 4).

Nakata's (2007, p. 199) model for a "cultural interface" offers considerable theoretical scope for examining the space between cultural systems and modalities. This "cultural interface" is

A multi-layered and multi-dimensional space of dynamic relations constituted by the intersections of time, place, distance, different systems of thought, competing and contesting discourses within and between different knowledge traditions, and different systems of social, economic and political organisation.

During 2006, I worked with some Aboriginal people in the Kimberley region of far north Western Australia I was engaged in a project to develop guidelines and protocols for the protection of Aboriginal knowledge related to language. Over the course of several months, I had conversations with elders from different language groups, hearing their stories of their country and culture. As I listened, it seemed to me that these people were talking about their country as a way of being in, of, and on that country, enacting or (re)-enacting their connections with it. Through talking it, they were, in a sense, walking it through speech, words of language, recalling and depicting aspects of the topography, of the land, the plants and animals. They also spoke about the times past, describing such aspects as wet and dry season camps, different types of fire, bush tucker, and the old ways. These old peoples' knowledge both informs their intricate and deep understandings of their particular country, and is nourished by it. The knowledge situates them historically and temporally, and reaffirms their place in the world. It reaches back into memory and consciousness, but is also in the here and now.

Listening to those people talking about country reaffirmed for me that there is a vast domain of Indigenous knowledge that lies outside, or beyond the scope of classification, description, translation and legislation in the Western system. Where initially I was struck by what appeared to be repetition in the telling about their knowledge of country, I soon realised that this repetition is crucial to the ways in which they express meanings in the holding of, and sharing of their knowledge. Their articulation of knowledge of country was very much a performance: a movement back and forth, and a folding, or turning in upon itself, and upon the external world. The cadences, intonations, and patterns of speech are intrinsic qualities unique to every performance. There is a movement back and forth, inside and out, in the presentation of those old peoples' knowledge. The expression of their knowledge often appeared to possess a kind of interior quality, as if they were in dialogue between themselves as individuals; in a sense, their interior selves, the collective culture of their particular group, and the wider space of other listeners and observers.

When reflecting on these performances, on the ways in which people articulated their deep knowledge of country, it also confirmed my view that what is termed "Indigenous knowledge", or "traditional knowledge" is not a single, homogenous, uniform entity. There is a spectrum of different types of knowledge that embraces elements that may be described as "new", or "modern" or modernising knowledge, "old", or "traditional" knowledge, tacit, implied or existing knowledge, the "ordinary" knowledge of the mundane, of the everyday, and deep, or profound knowledge. All of these elements are constantly shifting and realigning, and are juxtaposed in complex ways. No knowledge system is comprised of just one dimension; it is a process, or an activity in which there is a constant, often imperceptible shifting and re-aligning between and among different kinds of knowledge.

As knowledge is articulated and transmitted through the vehicles of language and speech, then the roles of such critical devices as memory and recall also require consideration. Repetition too, is an important aspect of performance in an orally based culture (e.g., Ong, 2002). The repetitions, patterns and cadences of the verbal articulation of cultural knowledge provide the keys to Aboriginal peoples' understandings of, and holding of their knowledge. These textures importantly also provide markers for, and enhance, and aid listeners' understandings.

Considering all these qualities, some fundamental questions arise: If Indigenous knowledge is described and delineated in terms of regimes for "protection", what are we seeking to "protect" here, and why? What, if any, is the role of property and the law? The notion of protection requires a context. Legal protection is contingent upon the concept of Western ideas about property and ownership: the rights and interests of some as against the rights and interests of others. Who is to do the protecting, and how? What is it in need of protection from? A focus on protection in the legal domain, I am suggesting, creates a discourse in which Indigenous knowledge is defined, discussed and debated as a "negative" or "oppositional" entity, rather than as a system of meaning, values, practices and understandings in and of itself, as an intrinsic part of culture. An emphasis on protection in terms of property transforms a cultural system of meanings, values and expressions, into a discourse of potential conflict, division and competition.

Can the fragmentation, classification and typological approach to Indigenous heritage so ingrained in legal and policy developments adequately weld together the intricate and complex connections between things, places, persons, and have regard to the entire range of emotive, personal configurations so apparent in hearing a spoken account of Indigenous knowledge? The 
endeavours to understand and interpret Indigenous cultural systems in law and policy are challenges of cultural translation. It is not just a matter of finding a correspondence between one language and another; it requires developing ways in which the deep meanings and contexts of Indigenous cultures can find equal space with other knowledges (e.g., Davis, 2001).

As I was listening to elders talking on country in the Kimberley, I noticed their capacity to be particularly present in, and engaged with their country in powerful and compelling ways. Taking all these experiences of listening to these people into account, I reflected that their knowledge, so deep and profound, and personal, is not something that can, or indeed should readily be defined by legal or policy documents, intellectual property, or regimes for protection. How can legislation and policy capture such organic, human qualities of nostalgia, loss, melancholy, feelings, intuition, remembrance, emotion, and all the complex and subtle nuances of speech and language that embody, are embedded in, and give expression to these qualities? Is it possible for law and policy to encapsulate the deep and profound connections between the knowledge itself, the bearers of this knowledge, and its source-the place wherein the knowledge resides, is formed, and which gives it meaning? Can legal and policy documents indicate something of the intricate relationships between people, place, and the world of spirits and ancestors?

It seemed to me, listening to the old peoples' talking, and watching them as they spoke, that they were not merely talking about "their country"; they were living it, experiencing it through language and speech. And at the same time, they were also engaging with, and sharing it with me, an outsider, a stranger. Aboriginal peoples' cultural knowledge and heritage creates a framework within which they deal with others-not only of their own group-but also from the wider community. I want to develop this idea that Indigenous knowledge concerns ways of engaging with the world as the basis for my argument that the recognition and understanding of this knowledge might be better advanced not only in terms of legal protection and the formulation of definitions, but also by creating the conditions that encourage dialogue, negotiation and partnerships between the knowledge holders and their communities, and the wider community.

To further pursue my idea about understanding Indigenous knowledge in terms of dialogue and negotiation, I want to take a step back, and explore some of the ways in which the terms and concepts - what I call the discourses - of law and policy, and of administration, seek to interpret, translate, perhaps give effect to, the complexity that is Indigenous knowledge. I am broadly arguing that existing and emerging legislative and policy discourses - at all levels, international, regional, national and local - tend to fragment and dismember the totality of Indigenous knowledge, and constrain it within the technical-legal-administrative domains of "property", and through the production of taxonomies and inventories. The tendency is to situate Indigenous knowledge in Western legal and policy discourses as a disembodied entity, separated from its living, dynamic contexts, out of place and time. Indigenous knowledge in these developments is not recognised as a way of engagement with the world and with others, as forms of participation, as ways of incorporating difference into a subtle and complex system of meaning and values.

I am arguing for greater recognition of the intrinsically emotive and affective qualities of Indigenous knowledge as distinct, and inherently unique from many Western discourses. However, at the same time I also want to stress the equity of these different knowledge systems. Indigenous knowledge holders are also intellectuals, philosophers, and scientists, and their knowledge systems are equally systems of law, and science. By giving greater attention to the expressive and emotive qualities of Indigenous knowledge, I am not in any way diminishing the validity of this knowledge tradition in opposition to, or contrast to Western epistemologies (e.g., Davis, 2006). Rather, I am arguing that the qualities of Indigenous knowledge that give it texture and dynamism, and that situate it in place and/or time, are not adequately represented in current discussions around protection of such knowledge. Indigenous knowledge systems, like all such systems, are juxtaposed within wider realms of meaning, and are not remnants, or fixed entities that are immutable, and separated from history, place, and people. As Dei (2000) has noted, "Indigenous knowledges do not 'sit in pristine fashion' outside of the effects of other knowledges" (p. 111).

A consequence of focussing discussions about Indigenous knowledge on legal and administrativebureaucratic mechanisms for protection, as forms of property, is that such knowledge is fragmented into discrete entities that are amenable to classifying and inscribing into familiar regimes of Western law and policy (Davis, 2006). In advocating a shift from these fragmenting and classifying approaches, I consider the possibility of approaching Indigenous knowledge not as a form of "property", or as something that is defined negatively as an entity in need of protection, but rather, as a system of practices, performances, and ways of enacting the world and engaging with others through relationship, dialogue, negotiation and expression. To support my argument I present a brief survey and critique of some of the discourses of law and policy that focus on "protection", and which deploy terms such as "cultural property", or "intellectual property" and which seek to define these primarily through the formulation of inventories and typologies.

Many discussions and debates about Indigenous knowledge focus on the idea that Indigenous knowledge is primarily something that is in need of protection. This is an oppositional strategy in which Indigenous knowledge is not understood as a distinct realm of values, meanings, behaviours and rules in and 
of itself, but is, rather, an entity that is defined in terms of being under threat from development, or from the encroachment and influences of the dominant world. In order to devise measures for protection, much attention is given to formulating definitions of Indigenous knowledge. These definitions are frequently based on, or require for their formulation, the production of taxonomies, of lists and inventories of what Indigenous knowledge is thought to comprise.

There is no doubt an alarming increase in the disappearance or erosion of Indigenous knowledge, the disappearance of the elders and other knowledge holders and custodians, and diminishing opportunities for Indigenous people to practice and transmit their knowledge. There is an urgent need to reduce threats to Indigenous peoples' lands, environments and communities as these diminish their capacity to retain and to enact their intricate understandings of their worlds. The relevance and meaning of Indigenous peoples' special knowledge systems is limited by the expansion of modernising influences, and destabilised with the corroding influences of alcohol, substance abuse, and the attendant social problems. There is unquestionably a growing need for the global community to act more decisively in preserving the world's biodiversity and variety of ecosystems, and to support and expand programs and policies for Indigenous language and cultural maintenance, and for community capacity development to enhance opportunities for Indigenous people to retain the integrity of their knowledge systems.

At the same time, there is a burgeoning of legal and standard setting developments and institutions concerned with developing measures for the protection of Indigenous knowledge, and for what is termed "Indigenous intellectual property". Many of these developments are occurring at the international level-predominantly through the Secretariat of the United Nations Convention on Biodiversity (the CBD), and the World Intellectual Property Organisation (WIPO) - and also through such agencies as the United Nations Permanent Forum on Indigenous Issues, and the UN Conference on Trade and Development (UNCTAD). Within this growing body of work there is a major theme: the formulation of mechanisms and measures for protection of Indigenous knowledge, and within this, a search for definitions of this knowledge, and with definitions often based on a re-iteration of inventories and catalogues of what is thought to be the "content" of Indigenous knowledge.

\section{Discourses on protection and preservation}

I support the development of legislative measures for protection, and of standards for recognition of Indigenous knowledge. However, at the same time I also want to argue that the notion of protection carries with it certain assumptions, and that these assumptions emphasise content at the expense of form, meaning and context for Indigenous knowledge. This focus on what might be termed a typological or classificatory approach to Indigenous knowledge, as a framework for developing a protection-based regime needs to be re-examined.

\section{The 2003 UNESCO Intangible Heritage Convention}

To illustrate my questioning of the notion of protection and its implications for a classificatory approach to heritage, I will consider one international instrument that has come into force in recent years, which provides for protection of intangible heritage - and therefore is particularly relevant to Indigenous knowledge. The UNESCO Convention on the Safeguarding of the Intangible Cultural Heritage was ratified by the UNESCO General Assembly on 17 October 2003. This Convention acknowledges in its Preamble the relationships between physical and tangible heritage, as it considers "the deepseated interdependence between the intangible cultural heritage and the tangible cultural and natural heritage' (UNESCO 2003). This is a useful provision, since it is consistent with earlier standard setting developments in Indigenous heritage, such as the United Nations studies by Special Rapporteur Erica-Irene Daes. In a 1993 report Daes had proposed that "all elements of [Indigenous] heritage should be managed and protected as a single, interrelated and integrated whole" rather than as separate elements designated by terms such as "cultural property" and "intellectual property" (Daes, 1993, p. 7, para 31).

Despite the comprehensive reports such as those of Daes advocating maintenance of the integrity and totality of Indigenous heritage, the tendency in legislative and policy developments has nonetheless still been to fragment and compartmentalise Indigenous knowledge, and to devise lists and inventories in order to develop measures for protection.

The Convention on Safeguarding Intangible Heritage is a case in point. This Convention is not specific to Indigenous heritage, but it does illustrate the kind of problem I am discussing in heritage law and policy more generally. Despite its rhetoric of integrating different elements of heritage, and having proposed that the interrelatedness of intangible and tangible heritage be maintained, the Convention then moves on to definitions, where "safeguarding" is defined as:

Measures aimed at ensuring the viability of the intangible cultural heritage, including the identification, documentation, research, preservation, protection, promotion, enhancement, transmission, particularly through formal and non-formal education, as well as the revitalization of the various aspects of such heritage (Art 2(3)). 
The Convention then proceeds, like many instruments of this type, to advocate the inventorying of intangible heritage as a means of "ensuring the safeguarding" of this heritage, proposing that States shall:

Identify and define the various elements of the intangible cultural heritage present in its territory, with the participation of communities, groups and relevant non-governmental organizations (Art 11).

\section{And that:}

To ensure identification with a view to safeguarding, each State Party shall draw up, in a manner geared to its own situation, one or more inventories of the intangible cultural heritage present in its territory. These inventories shall be regularly updated (Art 12).

This cataloguing, says the Convention, will be formalised into a "List of the Intangible Cultural Heritage of Humanity", to "ensure better visibility of the intangible cultural heritage and awareness of its significance, and to encourage dialogue which respects cultural diversity" (Art 16). This typological and classificatory approach to defining intangible cultural heritage as a way of protecting and preserving it is also common to many non-binding ("soft-law") instruments, including the Declaration on the Rights of Indigenous Peoples, the Mataatua Declaration, and others.

The taxonomic and inventorying provisions in the Convention on the Safeguarding of Intangible Heritage appear to perpetuate, or even to encourage a classificatory approach to intangible heritage. This is despite a view resulting from a 1999 evaluation of this Convention's predecessor instrument - the 1989 UNESCO Recommendation on the Safeguarding of Traditional Culture and Folklore - that the Recommendation "places too much emphasis on documentation and archiving and on the products rather than the producers of traditional culture" (Aikawa, 2004, p. 140).

In all this classifying, documenting and inventorying, what of the role of the people themselves, the knowledge holders and owners? As Aikawa reminds us, "recognition and respect for the active participation of grassroots practitioners in the production, transmission and preservation of their cultural expressions are essential to ensure the safeguarding of intangible cultural heritage" (Aikawa, 2004, p. 140).

Protection and preservation discourse in international standard setting

Another key international instrument relevant for Indigenous knowledge is the United Nations Convention on Biological Diversity (the CBD). This
Convention, at Article 8(j) encourages State Parties, "subject to national legislation", to:

Respect, preserve and maintain knowledge, innovations and practices of indigenous and local communities embodying traditional lifestyles relevant for the conservation and sustainable use of biological diversity and promote their wider application with the approval and involvement of the holders of such knowledge, innovations and practices and encourage the equitable sharing of the benefits arising from the utilisation of such knowledge, innovations and practices (CBD 1993, Art 8(j)).

The absence of references to place, historical contexts, and the dynamism of change in these CBD provisions on traditional knowledge are notable. The CBD also uses the language of preservation, and has insufficient emphasis on recognising and strengthening the rights of the producers and creators of the knowledge. Once again, Indigenous knowledge is linguistically and semantically trapped in a museological discourse that disembodies it and alienates it from its context in living cultures and societies.

The UN World Intellectual Property Organisation (WIPO) also employs the language of protection, although it is aware of some of the problems with protection. In a 2006 Information Note, WIPO states that "sometimes activities by museums and cultural specialists do not take adequate account of [Indigenous peoples'] rights and interests, and that documenting and displaying, say, a traditional song or a tribal symbol, make them vulnerable to misappropriation" (WIPO, 2006, p. 2). The work of WIPO, while commendable in many ways, also illustrates the way in which heritage protection has become synonymous with the development of legislative regimes, particularly those of intellectual property. One commentator, anthropologist Michael F. Brown argues that "the goal of rectifying civil wrongs thrusts heritage protection into the provinces of intellectual property and tort law" (2005, p. 44) Brown worries that the Intangible Heritage Convention "portrays intangible heritage as an objectified resource amenable to modern management techniques" (2005, p. 48). He protests, "in such a legalistic vision, heritage cannot be protected until it is thoroughly documented", and consequently, "one struggles to imagine how it will protect cultures as living, dynamic systems" (2005, p. 48).

In much of the debate and discussion, Indigenous knowledge is transformed into Western legal concepts of intellectual property. There has been a lot written about the incompatibilities between Indigenous knowledge and intellectual property laws. Essentially the mismatch highlights the fact that these are fundamentally radically different systems and worldviews; the one (Indigenous 
knowledge) having to do with relationships between humans, their environments, and their cosmologies; the other being a system devised to foster and encourage commercial transactions and to protect individual rights.

Some historical examples of the typology approach to Indigenous heritage

The use of classification and inventorying as a means of defining Indigenous knowledge and heritage has been perpetuated for many years, both internationally and in Australia. On a more optimistic note, there have also been some attempts at devising approaches to protection and recognition in a more integrated or holistic way. In 1969 in Australia for example, there was an attempt to legislate for protection of an integrated entity to include "work of art", "ritual, ceremony, dance or drama", "record in any form of such ritual, ceremony, dance or drama", "design", and "area of land". This so-called "Traditional Aboriginal Property" legislation was proposed by H. C. Coombs. It was a far reaching proposal for the time, seemingly designed to encapsulate the intricate relationships in Aboriginal society between art, land and sacred sites, and to recognise these as elements of an integral cultural system. The recognition within the political/administrative context of these connections between the different domains of Aboriginal culture was influenced at least in part by the work and writings of some anthropologists during the 1950s and 1960s, such as Ronald Berndt, A. P. Elkin and many others. Coombs and others, such as anthropologist Stanner, had understood the connections between art, land, and the sacred in Aboriginal society, and had sought to link these in the proposed legislation. Although the "Traditional Aboriginal Property" proposal was still oriented towards the notion of Aboriginal cultural heritage as "property", and adopted a classificatory approach, it was nonetheless progressive in its recognition of the links between different elements, especially between the sacred and physical domains. Unfortunately the proposal languished and did not amount to anything (Davis, 2007, p. 282-84).

The impetus for this development was in part provided by a growing realisation during the 1950 s among policy makers and anthropologists of the importance of the sacred in Aboriginal society, and of the role of sacred sites. In part at least, this emerging consciousness was triggered by growing interests from the mining sector, notably in bauxite deposits in the Northern Territory, and an increasing politicisation by Aboriginal people (predominantly Yolngu people) of their rights in regard to their lands and sites where the proposed mining would occur. Anthropologist Ronald Berndt was engaged by the authorities to conduct surveys of sacred sites in the relevant areas of Arnhem Land, and his reports furnished lists of such sites. These lists subsequently formed the bases upon which heritage legislation was introduced at both Commonwealth (the Aboriginal Land Rights
Act 1975 (Northern Territory)) and Territory (the Sacred Sites Act 1989 (NT)) levels (Davis, 2007).

Some years later, in the early 1980 s there was another attempt to formulate law and policy to protect Indigenous heritage in a more integrated way. That development had resulted partly through debates over the previous decade about the problems in protecting the rights of Aboriginal artists, and the misuse of their designs. While aware of the problematic nature of using the term "folklore" a committee formed to examine this issue explained that:

Use of the term "folklore" recognises that traditions, customs and beliefs underlie forms of artistic expression, since Aboriginal arts are tightly integrated within the totality of Aboriginal culture. In this sense folklore is the expression in a variety of forms of a body of custom and tradition built up by a community or ethnic group and evolving continuously (Report of the Working Party on the recognition of Aboriginal Folklore, cited in Davis, 2007, p. 295).

The report went on to say that "the word 'folklore' has been adopted as a compromise meeting the conceptual and international legal requirements for such a term" (Report of the Working Party on the recognition of Aboriginal Folklore, cited in Davis, 2007, p. 295). Although the proposed "Folklore Act" retained the typological approach to defining Indigenous heritage, that legislative development was relatively progressive in seeking to encompass, in an inclusive way, a number of different elements, including the tangible and intangible in Indigenous heritage. It was also ahead of its time in that it sought to establish a mechanism, or process by which rights and interests in "Aboriginal folklore" were to be ascertained and determined through a tribunal system. Aboriginal people, in this system, would be compensated for use of their "folklore" by provision of benefits. This was a more potentially appropriate way of protecting Aboriginal peoples' rights and interests than the more "top-down" or prescriptive approaches common to legislation today.

\section{The problem with categories}

I am arguing against dividing Indigenous heritage into categories for the questionable purposes of transforming them into disembodied legal entities. I am also concerned that this transformation requires, or depends on the classification, inventorying and documenting of Indigenous heritage, so that the latter ceases to exist as little more than an encyclopaedic legal category, disembodied from its cultural, historical and human contexts. There is some usefulness in categorising Indigenous heritage in limited ways for the purposes of analysis, and in order to gain some ground in reforms to enable prevention of misuse. There is, for 
example, a growing interest by Indigenous peoples, and others, in exploring the role of community databases, registers and other mechanisms for documenting and recording Indigenous knowledge and cultural heritage as a means of defending it against misuse through bad patents or other forms of exploitation. Databases and registries are being developed, or considered at various levels, international, regional, national and local. The arguments for and against these measures are complex, and cannot be adequately discussed in this paper (e.g., Brahy, 2006; Hansen \& VanFleet, 2003; UNU-IAS, 2003). These "defensive protection" measures and mechanisms are worth examining in more detail in another place. However, an over-determined approach that defines and regulates Indigenous heritage only as discrete elements does not serve the interests of the people whose heritage it is.

It is not only the compartmentalising and fragmenting of Indigenous heritage that is a concern. The unexamined adoption of terms and expressions within international standard setting activities and work programs risks further alienating Indigenous knowledge from its place - based contexts grounded in the particularities and contingencies of community, locality and time. The growing program of international laws seeking to develop standards for recognition and protection of Indigenous peoples' rights in culture and heritage is crucial, and welcome. But at the same time, there is a risk that this internationalisation will also tend to promote a universalising or essentialising of Indigenous culture and heritage at the expense of acknowledging its place-based and localised nature.

The problem with emphasising protection is that it privileges the relationship between heritage and property - and often equates the two. The result of this is that, as a property right, the problem of protection becomes an overwhelmingly legal one. The current tensions and anxieties in international levels bear witness to this, wherein Indigenous knowledge is discussed primarily within two separate United Nations agencies: the Convention on Biological Diversity (CBD), and the World Intellectual Property Organisation (WIPO). While the CBD has made some important advances in standard setting that can potentially realise and advance recognition of the multiple, pluralistic and complex human dimensions of traditional knowledge, the work of WIPO is conducted within the more constrained framework of intellectual property rights.

In recent years the $\mathrm{CBD}$ has, through the excellent work of its Working parties on Access and BenefitSharing, and on Traditional Knowledge respectively, developed standards for access to genetic resources and fair and equitable sharing of the benefits arising out of their utilisation (the Bonn Declaration), and for cultural, environmental and social impact assessment (the Akwe Kon Guidelines). Although these are both voluntary guidelines, they are nonetheless of critical importance in that they shift the debate beyond the limitations of deterministic intellectual property and legal regimes, towards greater incorporation of human and cultural dimensions. They also encourage nationstates to consider the important roles of Indigenous and local peoples' customs and traditions, and authority and decision-making structures.

I am arguing then for a balance between the universal and the particular. Universals can enable or facilitate dialogue, cross-cultural comparisons, and a correspondence or integration of otherwise inherently disparate knowledge and cultural systems. However, these universals must be grounded in the contingencies and complexities of distinctiveness: the specific relationships between peoples, place, locality, and the trajectories of history. In problematising the received terms and categories of law and policy discourses, I am arguing for the creation of a space in which there can be greater focus on what is in common, while at the same time allowing for recognition of the distinct expressive qualities of Indigenous knowledge. I am suggesting the development of a new language of understanding, interpretation and translation, that can facilitate a better integration between Indigenous knowledge, and Western scientific knowledges. I am interested in how such engagement between Indigenous, and other forms of knowledge, can contribute to natural resource management and environment and heritage conservation, planning and management. If the received categories such as "protection" are adopted without interrogating them to ascertain more precision as to what they actually mean, and imply in practice, this is an impediment to progress in working different knowledge traditions together. An uncritical acceptance of notions such as "protection" often results in work on Indigenous knowledge being confined to merely recitations or inventories of "current developments" listing international, regional, and national laws and policies without analysis or interpretation.

\section{Protection and property}

The development of legal discourses for protecting Indigenous knowledge generally requires, or depends upon a transformation of Indigenous knowledge into property, a commodity for economic transactions. A significant focus in standard setting developments and the emergence of regimes for protection is on intellectual property. This implies an equation between Indigenous knowledge and commodity, and therefore creates a discourse of transaction, of market driven imperatives, and commercial interests.

Legal developments, policy-makers, and bureaucrats grapple with choice of terms, arguing over the relative merits of encapsulating Indigenous cultural traditions within such rubrics as "intellectual property", "cultural property", or "cultural heritage" (e.g., Blake, 2002; Frigo, 2004). Frigo, for example, argues for "cultural heritage" as the preferred term, stating: 
It is evident that the concept of cultural heritage, if compared to that of cultural property, is broader in scope, as it expresses a "form of inheritance to be kept in safekeeping and handed down to future generations". Conversely, the concept of cultural property is "inadequate and inappropriate for the range of matters covered by ... cultural elements (like dance, folklore, etc.) more recently deemed entitled to legal protection at the international level (Frigo, 2004, p. 369).

It is worrying that international developments and programs of work continue to agonise over the use of terms, and perpetuate the distinctions between them. Both UNESCO and WIPO illustrate these terminological anxieties.

Beyond the confines of protection: Indigenous knowledge, place, dialogue, and engagement

The philosopher Edward S. Casey (1993) has argued for a return to the importance of place in the Western imagination. He makes an eloquent case for the significance of place, tracing its genealogy back to ancient times, and refiguring place in Western thought. The concept of place, of situatedness, is critical for not only understanding the dynamic and intrinsic qualities of Indigenous knowledge, but also for developing a more engaged dialogue regarding the rapprochement between Indigenous, and other knowledge systems in the context of land, heritage, and natural resource management and conservation.

If Indigenous knowledge is returned to its context in place, and time, and understood as systems of relationship and dialogue, what, if any scope might there be in recognising and supporting these qualities within the dominant discourses of Western policy and programs? Greater opportunities for engagement with Indigenous knowledge as forms of relationship and dialogue can be found through the mechanisms of agreement-making, treaty-making and the development of negotiated partnerships. There is scope for formalising and supporting these types of approaches in developing creative approaches consistent with, and that domestically implement the Convention on Biological Diversity, and potentially through the native title process. We can look to some activities occurring at international levels in agreement-making and equitable benefitsharing over bio-resources, collective and communal rights, and Indigenous knowledge and practices. There is a great deal more that needs to be done in Australia to develop these kinds of approaches.

There needs to be recognition of, and support for Indigenous customary laws and practices, especially in regard to modes of governance, community authority and decision-making processes and structures, permission giving, prior informed consent mechanisms and communal structures for holding and managing knowledge, resources, and heritage. Dialogue and engagement through agreement-making allows the possibility of working two different knowledge traditions together - Indigenous knowledge and Western knowledge - for the wider benefit of sustainable development and livelihoods, natural and cultural resource management, and land, environment and heritage conservation, management and planning.

How can we understand Indigenous knowledge as sets of relationships, and as ways of being in place and in history? In addition, what, if any, practical implications might such an understanding present for natural resource management, cultural heritage, land and environment planning, management and conservation? I would advocate a need to look more seriously at devising new approaches - what have been called sui generis approaches - that lie outside, or beyond the constraints and limitations of conventional intellectual property laws. There is an established and growing body of work, and emerging standards for such sui generis approaches, and much scope for devising a good model for the Australian context. The ground breaking work of Posey and Dutfield (1996) in developing integrated approaches to Indigenous knowledge recognition that combines creative uses of human rights instruments, soft law, and contract and agreement making, and international and regional examples, provides just one model for examining the benefits of trialling such sui generis approaches in the Australian context. There is also a growing body of work at the international level that is exploring the possibility of such approaches. Sui generis approaches may include among their key elements: recognition of Aboriginal customary laws; provisions for free prior informed consent; recognition of human (especially cultural social and economic) and moral rights; environmental protection and biodiversity conservation. Examples of some regional regimes are the African Union Model Law on Rights of Local Communities, Farmers, Breeders and Access (2000), the Andean Decision 391, Common Regime on Access to Genetic Resources (1996), and the Costa Rica Biodiversity Law (1998) (e.g., United Nations Environment Program (UNEP, 2005), for more details).

As part of developing a sui generis approach, there is potential for supporting partnership and negotiated agreement-making arrangements integrating Indigenous, and non-Indigenous knowledge systems, through legislation such as the Commonwealth's Environment Protection and Biodiversity Conservation Act 1999. Although this legislation regulates access to genetic resources primarily to support trade and commerce, it should be reviewed (especially the relevant Regulations) in order to assess its potential to provide avenues for equitable benefit-sharing partnerships with Indigenous peoples, that uphold Indigenous peoples' rights and interests in their bio-resources, and associated knowledge and practices, and that are based in recognition of their customary laws. 
Moving beyond the confines of intellectual property and classificatory and typological approaches can allow a space for exploring the notion of Indigenous knowledge as sets of relationships, obligations, and contingencies. The dimensions of Indigenous knowledge that are often absent in the international and national legal regimes include those such as nostalgia, memory, authority, responsibility, and history. A shift away from property and protection regimes can enable a focusing on these qualities, and on the possibility of acknowledging these in law and policy.

\section{References}

Agrawal, A. (1995). Indigenous and scientific knowledge: some critical comments. Indigenous Knowledge and Development Monitor, 3(3), 1-9.

Aikawa, N. (2004). An historical overview of the preparation of the UNESCO International Convention for the Safeguarding of the Intangible Cultural Heritage. Museum, 56, 1-2.

Asia/Pacific Cultural Centre for UNESCO. (2006). UNESCO-ACCU Expert Meeting on Community Involvement in Safeguarding Intangible Cultural Heritage: Toward the Implementation of UNESCO's 2003 Convention, Tokyo, Japan, 13-15 March 2006. Information Note prepared by the Secretariat of the World Intellectual Property Organization. Retrieved 7 July, 2008, from http://www.accu.or.jp/ich/en/pdf/c2006Expert_UEMURA. pdf

Blake, J. (2002). On defining the cultural heritage. International and Comparative Law Quarterly, 61, 61-85.

Brahy, N. (2006). The contribution of databases and customary law to the protection of traditional knowledge. International Social science Journal, 58(188), 259-282.

Brown, M. F. (2005). Heritage trouble: Recent work on the protection of intangible cultural property. International Journal of Cultural Property, 12, 40-61.

Casey, E. S. (1993). Getting back into place: Toward a renewed understanding of the place-world. Bloomington, IN: Indiana University Press.

Daes, E. (1993). Study on the protection of the cultural and intellectual property of Indigenous peoples. United Nations document E/CN.4/Sub.2/1993/28, 28 July 1993.

Davis, M. (2001). Law, anthropology, and the recognition of Indigenous cultural systems. In R. Kuppe \& R. Potz (Eds.), Law and anthropology: International yearbook for legal antbropology 11 (pp. 298-320). The Hague, SH: Martinus Nijhof Publishers.

Davis, M. (2006). Bridging the gap or crossing a bridge? Indigenous knowledge and the language of law and policy. In W. V. Reid, F Berkes, T. J. Wilbanks \& D. Capistrano (Eds.), Bridging scales and knowledge systems: Concepts and applications in ecosystem assessment (pp. 145-163). Washington, DC: Island Press.

Davis, M. (2007). Writing heritage: The depiction of Indigenous heritage in European-Australian writings. Melbourne, VIC: Australian Scholarly Publishing and the National Museum of Australia.

Dei, G. (2000). Rethinking the role of Indigenous knowledges in the academy. International Journal of Inclusive Education, 4(2), 111-132.
Ellen, R., \& Harris, H. (2002). Introduction. In R. Ellen, P. Parkes \& A. Bicker (Eds.), Indigenous environmental knowledge and its transformations: Critical anthropological perspectives (pp. 1-29). Amsterdam: Harwood Academic.

Frigo, M. (2004). Cultural property v cultural heritage: a "battle of concepts" in international law. IRRC, 86(854), 367-378.

Gibson, J. (2005). Community resources: Intellectual property, international trade and protection of traditional knowledge. Aldershot, NSW: Ashgate Publishing Limited.

Hansen, S. A. \& VanFleet, Justin W. (2003). Traditional knowledge and intellectual property: A handbook on issues and options for traditional knowledge holders in protecting their intellectual property and maintaining biological diversity. Washington, DC: American Association for the Advancement of Science.

Nakata, M. (2007). Disciplining the savages: Savaging the disciplines. Canberra, ACT: Aboriginal Studies Press.

Ong, W. J. (2002). Orality and literacy. London: Routledge.

Posey, D. A., \& Dutfield, G. (1996). Beyond intellectual property, toward traditional resource rights for Indigenous peoples and local communities. Ottawa, ONT: International Development Research Centre.

Pratt, M. L. (1992). Imperial eyes: Travel writing and transculturation. London: Routledge.

United Nations Educational Scientific and Cultural Organization. (2003). Convention For the Safeguarding of the Intangible Cultural Heritage. Retrieved 7 July, 2008, from http://www.unesco.org

United Nations Environment Program. (1993). Convention on Biological Diversity. Retrieved 7 July, 2008, from http://www.cbd.int.

United Nations Environment Program. (2005). Development of elements of sui generis systems for the protection of traditional knowledge, innovations and practices. UNEP/CBD/WG8J/4/7, 24 November 2005. Retrieved 7 July, 2008, from http://www.cbd.int/doc/meetings/tk/wg8j-04/information/ wg8j-04-inf-18-en.doc

United Nations University-Institute of Advanced Studies. (2003). The role of registers and databases in the protection of traditional knowledge: A comparative analysis. Tokyo: United Nations University Institute of Advanced Studies.

\section{About the author}

Michael Davis is currently a researcher with Jumbunna Indigenous House of Learning at University of Technology Sydney. He is developing a research agenda on Indigenous knowledge, biodiversity and natural resource management, and writing policy discussion papers in this area. His research interests are in Indigenous knowledge and other knowledge traditions, critiques of law and policy, Indigenous/ European histories, and policy in Indigenous collective heritage and environmental rights. Davis has wideranging experience in this field, having worked in the public sector, as an independent consultant, and with Indigenous community organisations. He has a number of published works in this area. 